\title{
Reflective Practices at Tertiary Level: A Gender Wise Comparison
}

\author{
Mahek Arshad* \\ Allah Bakhsh Malik ${ }^{* *}$
}

\begin{abstract}
The study aimed to determine reflective practices of teachers at tertiary level and to determine the difference in reflective practices of teachers on the basis of gender. Present study was descriptive in nature. Population of the study comprised of all the 5404 teachers teaching in universities of Islamabad. $12 \%$ of teaching faculty was selected by using proportional stratified sampling technique. Questionnaire developed by Wilkes and Chapman (2015) was adapted as research tool. Findings revealed that tertiary level teachers were practicing reflection in-action and reflection on-action, using different tools of reflection, they practice reflection by examining others and own perspectives and question assumptions of others as well as their own related with their teaching. A significant difference was found among teachers by gender regarding their reflective practices. Male teachers were found better as compare to female teachers in their reflective practices. On the basis of findings of the study it is recommended that at tertiary level workshops and awareness seminars may be conducted to raise teacher's awareness of the importance and use of reflective practices in teaching especially for female teachers.
\end{abstract}

Keyword: reflective practices, tertiary level, gender, comparison

\footnotetext{
* Ph.D. Scholar, National University of Modern Languages, Islamabad. Email: mehakrshd@gmail.com

${ }^{* *}$ Professor of Education (Rtd), National University of Modern Languages, Islamabad.
} 


\section{Introduction}

The notion of reflective practices is one of the latest approaches to the professional development of teachers. It is not like the traditional approach of professional development where most of the time teachers remain the focal point and discussion revolves around only one topic and no attention is given towards any dialogue with colleagues and students. A teacher's reflective practice includes valuings opinions of colleagues, sharing of experiences, considering philosophies and thinking critically. Reflective practice helps a teacher challenge and study their own assumptions and thoughts about teaching. Reflection is a complicated process where emotion and cognition are related and connected. Reflection is a purposeful pursuit; this is not idle wandering or activity of day dreaming, but a targeted and meaningful activity (Bound, Keogh \& Walker, 1985).

Reflection is the thinking process involved in everyday life and is considered more valuable than the ordinary knowledge (Rashidi \& Javidanmehr, 2012). Many kinds of reflections in the professional context seem to have two main purposes that include changes that are made to improve practice and further develop self-knowledge and understanding. Johns (1995) believes that reflection is a way to think of something to find out some differences and try to find an answer and clarification. The major purpose of reflection is to expose the interchange of internal ideas that build the daily practices of a person. People give reaction and act according to their reasonable internal reflections. This is called instinct reasoning (Brookfield, 1995).

Gender diversity includes both biological phenotypes and their psychological characteristics. Thinking of teachers as reflective practitioners assume that teachers can both raise and resolve issues related to their educational practices. Present research was concerned with gender differences in practicing reflection among teachers. Feminine psychologists believe that women generally seem to have more experience in discussing, thinking and interpreting their inner thoughts and feelings (Belenky, Clinchy, Goldberger, \& Tarule, 1986). Three different studies were conducted by Csank and Conway (2004) in which they discussed the gender differences in the tendencies to reflect on self-descriptive traits and in the consequences of participating in this trait reflection, reported that women reflect more than men, changes has been observed in women after self-reflection but on the other hand men's self-definition in the entire situation have not changed after reflecting on their personality traits. On the other hand, Afshar and Farahani (2015) study indicated gender-based differences among teachers regarding reflective thinking and reflective 
teaching in which male teachers performed better as compare to female teachers regarding their reflective teaching and thinking.

\section{Literature Review}

The word "reflection" has its roots in a Latin word "reflectere," meaning turning round, bending back or turning backwards (Rushton \& Suter, 2012). According to Finlay (2008) the word "reflective practice" has a variety of meanings, ranging from independent reflection by professionals to a critical discussion with others and adds that practitioners may sporadically accept in a formal and clear manner. However, the understanding of "reflective practice" varies greatly among diverse fields and knowledge societies. Different and contradictory definitions and meanings of reflective practice can even be present in the same subject field. Reflection is a practice of intellectual process that is practiced to achieve our ends or attain any desired result. It is useful to well understand comparatively complex or shapeless notions, and is constructed primarily on the recycling of information, thoughtfully and possibly, the sentiments that people before now have (Moon, 2005).

Purpose of all kinds of reflections in the professional context seems to have two main purposes that include changes that are made to improve practice and further develop self-knowledge and understanding. Reflective practice is one of the strategies for teachers teaching at university. The ability to reflect on the action means participating in the practice of continuous learning, which is one of the characteristics of professional practice. This practice encourages practitioners to develop teaching as an insight. Reflective practice is considered to be a vital tool in the environment of teaching and learning, teachers learn from their own professional experience to a certain extent as compare to the traditional teaching (Schön, 1991). Zeichner and Liston (1996) believe that every teacher reflects in his or her own way so unreflective teacher does not exist.

Unlike traditional career growth, teachers often have a central place to focus on one concept without discussing it with colleagues and students. This method additionally encourages teachers to inspect their positive and negative teaching and learning experiences to get knowledge that why they incline to do things and why avoid others. Reflective practice is a method of individual improvement. There are many self-conscious, selfdevelopment factors in building one's opinion. Reflective practice needs uniqueness in the field and by keeping in view past experience teachers bring fresh changes to the methods of overcoming these problems (Bound, Keogh \& Walker, 1985). Reflection as a professional development 
strategy, through reflection, professionals will have the opportunity to explore, express and represent their own ideas and knowledge.

Every day, every hour, even every minute, teachers always try to solve the issues in the classroom. Reflective teachers not only think of how they are framed, but also think of how to solve immediate problems. Introspection means recognizing that the production of new pedagogical knowledge is not the exclusive property of universities, colleges and research development centers, rather it is a realization that teachers also have their own ideas, beliefs and theories that can contribute to improving teaching (Zeichner \& Liston, 2014). Reflective practice usually involves practical problems. As a result of reflection, practitioners become more informed because of the effective acquisition of relevant knowledge and are considered proficient. So reflection can sound valuable in different fields and industries by enabling the person concerned to reflect on the situation and is therefore very important for practice (Loughran, 2006). Reflecting in education require teachers to systematically think and logically, rationally and step wisely analyze their teaching and related scenarios (Korthagen, 1993).

Wilkes (2015) gives a model of reflective practices for reflective teachers by adding five characteristics which a reflective practitioner may possess and can assess himself by keeping in view these characteristics.

a. Reflection in-action and on-action: Reflections in action is denoted as present action that exists. Schön (1983) believes that it is a useful tool that can be used by a professional who must respond to an incident when it happens, rather than considering what happened and making changes later. In addition, reflection on action involves reflection on how to change practices after an event occurs because we reflect on actions and recall what we have done to determine how the knowledge in our actions may have contributed to unpredicted outcomes. Teachers tend to act reflectively and respond to what's happening around them. This may involve quick reflection because teachers participate in events or experiences. Teachers can take immediate action based on circumstances. This is a valuable way of thinking and learning about events. Teachers be likely to reflect on actions, followed by an extra thoughtful practice (Wilkes, 2015).

b. Tools for Reflection: Reflective practitioners use different tools to record reflection, implement reflection and improve reflection which may include reflective diary, reflective journal, theories, models, discussion with seniors and colleagues, observation, sound and video recordings and many others. Teachers use a series of reflective activities to gain insight into work. They tend to walk out of their own 
comfort zone, seek feedback, self-criticism, examines hypotheses, question the theory, and defy the status quo (Wilkes, 2015).

c. Examining others and own perspective: For a reflective practitioner it is important to broaden his horizon and come out of his comfort zone by examining and understand not only his own self-vies or selfjudgment about his teaching but to keep in mind others views about his reflective practices regarding teaching (Wilkes, 2015).

d. Questioning assumptions: Assumption is a natural belief in the world and it is also our position in it. Brookfield (1995) identified assumption analysis as one of the type of reflection; he described it as a challenge to teachers' beliefs, values, cultural habits, and social structure. Practitioners may consider more of the assumptions hidden in the opinions of others, as well as those expressed in the media, books, research, etc. Practitioners may be aware of the values, beliefs and attitudes of themselves and others and tend to examine their own beliefs and challenges elsewhere in the status quo (Wilkes, 2015).

e. Ability to reflect: Ability here means the available time and capacity of a reflective practitioner to make time for reflective activities regarding his teaching. Time, resources or deficiency of autonomy have a tendency to limit reflective actions. Practitioners may overcome barriers to reflection and thereby gradually improve learning and growth (Wilkes, 2015).

A study conducted by Odeh, Kurt and Atamtürk (2010) with 60 teachers at a Turkish university examines whether gender, length of experience, and qualification make a significant difference in the level of teacher reflection. The results show that gender, experience and qualification does not play any important role in teacher's reflection. Sammaknejad \& Marzban (2016) did a comparative case study of teachers' self-reflection on classroom management. The results show that female teachers have a positive attitude towards self-reflection, on the other hand, the responses of the male teachers to the classroom management questionnaire indicated that they had a more positive view on the issue. Experienced female teachers with the highest self-reflection and classroom management awareness; her reflective questions and classroom discipline diary proves this claim. Experienced men and women teachers are very close in the answer to the questionnaire, so they are "selfreflection and classroom management standards" attitude. Sharar (2012) conducted a study about introducing and improving reflective practices of teachers in a school at Chitral, it was found that reflective practice is a big challenge for the teachers to practice because of lack of knowledge about reflective practices and due to lack of time, professional development and 
pedagogical issues. Some studies like of Poyraz, Usta, (2013) and Rashidi, Javidanmehr, (2012) it was found that female reflective teachers outperformed men in reflective practices.

Ghaye and Lillyman (2000) explain that reflective practice is not only an academic or intellectual effort, but also a complex procedure involving individuals as a whole. Raelin (2002) expresses his point of view on the practice of reflection, believing that what has been done recently is the basis of future approaches; it mainly provides a research opportunity to understand the occurrence of events. Bolton (2010) expressed his view that reflective practice meant focusing attention on the day-to-day actions that led to professional development. When practitioners engage in reflective practice, it means that they take into account the work of the past and present circumstances in order to achieve better results (Beveridge, 1997). Reflective practice in their own actions and practice is called mediation. Donald Schön and David Boud were inspired by Dewey's work, who found reflection on all aspects of practice. Reflective practice is developed in connection with theory and practice. At first, only theory is the best, but with the passage of time, the actual work has been recognized, pragmatic knowledge has been recognized and considered to be the first step in professional development of reflection as a practice, focusing on practical work and thinking in which you can consider the consequences by looking at the various aspects of practical work.

Sellars (2014) emphasizes that reflection practices permit teachers to change their minds and encourage them to justify their beliefs. In his research, Narelle (2007) used photography as a tool for reflective practice and discussed how to use photography to trigger and assist teachers in professional practice, photos being taken by colleagues, themselves or students to provide different perspectives for classroom learning while generating issues, setting goals, and strengthening self-assessment and self-monitoring. Xavier (2009) proposed to use group discussion and reflection as a strategy to promote the emotional reconstruction of teachers' experience and to promote teacher development. Through group discussions and reflections with other participants, teachers discuss and evaluate current practices to explain and evaluate student activities, in result collaboration and community reflection emerged which facilitate problem-solving and the formation of dialogue thinking, leading to the shift of teachers' perceptions from the contextual characteristics of traditional teaching to more systematic awareness of curriculum behaviors. The problem under exploration is to determine the reflective practices of teachers at tertiary level on the basis of gender difference. 


\section{Objectives of the Study}

Objectives of the study were:

i. To determine reflective practices of teachers at tertiary level.

ii. To determine the difference in reflective practices of male and female teachers at tertiary level.

\section{Research Questions}

i. What are the reflective practices of teachers at tertiary level?

ii. Is there any difference between the self-reported reflective practices of male and female teachers at tertiary level?

\section{Methodology}

Present study was descriptive in nature in which survey method was used.

\section{Population of the Study}

Population of the study comprised of 5404 faculty members teaching in twenty-seven public and private sector universities (main and subcampuses) of Islamabad. Population of the study was divided in two major strata which include 3544 male and 1860 female teachers.

\section{Sample and Sampling Technique}

Proportional stratified sampling technique was adopted. $12 \%$ of both genders were selected for sample. Through this technique 650 teachers were selected which include 426 male and 224 female teachers. Gay (1987) suggests that $10 \%$ of large and $20 \%$ of small population as minimum may be selected. Krejcie and Morgan (1970) suggest sample size of 357 against population of 5000.

\section{Research Instrument}

Researcher adapted Reflective Practice Assessment instrument of Wilkes and Chapman (2015). Research instrument comprised of five subscales/dimensions which includes: Reflection in-action and on-action which comprised of seven items, Tools for reflection which comprised of ten items, examining others and own perspective regarding own reflective practices which comprised of nine items, questioning assumptions which comprised of seven items and Ability to reflect about own teaching which 
comprised of nine items. The scale was based on 42 items. Research was conducted after pilot testing of questionnaire and was reviewed by the experts before administration. Researcher conducted a pilot study to find out the reliability and validity of instrument. The instrument was found reliable as the value of Cronbach's Alpha Coefficient was .82. Reliability of subscales was .79, .86, .72, .76 and .73.

\section{Data Collection}

Data has been collected by personal visits to universities. 650 questionnaires were distributing among respondents and only 564 respondents returned questionnaires, further 24 questionnaires were rejected due to incomplete data. Total 540 questionnaires were filled properly and return rate was $87 \%$.

\section{Data Analysis}

After collecting the data from respondents it was tabulated and analyzed statistically by applying t-test and Mean.

\section{Results}

Table 1

Reflective practices of teachers at tertiary level

\begin{tabular}{lccc}
\hline Dimensions of Reflective practices & $\mathrm{N}$ & Mean & SD \\
\hline Reflection in-action and on-action & 540 & 3.52 & 0.78 \\
Tools for reflection & 540 & 3.38 & 0.76 \\
Examining perspectives & 540 & 3.64 & 0.72 \\
Questioning assumptions & 540 & 3.62 & 0.75 \\
Ability to reflect & 540 & 3.55 & 0.72 \\
Total & 540 & 3.54 & 0.64 \\
\hline
\end{tabular}

Table No. 1 describes reflective practices of teachers at university level. On first dimension of reflection 'reflection in action and on action', the majority of respondents indicate that they practice reflection (Mean score $=3.52$ ), whereas on second dimension which deals with the teachers use of reflective tool in their daily routine, majority of respondents indicate that they use different tools for reflection (Mean score $=3.38$ ). Majority responded that they practice reflection by examining others and own perspective regarding their teaching (Mean score $=3.64$ ). When inquired teachers view about the 
reflective practice of questioning assumption, the majority of respondents claim that they practice this feature of reflection (Mean score $=3.62$ ). The last dimension of reflection inquires about the ability of teachers to reflect, majority agrees that they have freedom to reflect (Mean score $=3.55)$. Overall mean results $($ Mean $=3.54$ ) indicates that teachers possess reflective characteristics and practicing reflection in their teaching.

Table 2

Reflective Practices (Comparison between Male and Female)

\begin{tabular}{lccccccc}
\hline Variable & $\begin{array}{c}\text { Group } \\
\text { (Gender) }\end{array}$ & $\mathrm{N}$ & Mean & $t$ & $d f$ & $\begin{array}{c}\text { Sig } \\
\text { (2-tailed) }\end{array}$ & Cohen's d \\
\hline Reflective & Male & 354 & 3.62 & 3.99 & 538 & .00 & 0.35 \\
Practices & Female & 186 & 3.39 & & & & \\
\hline
\end{tabular}

The above table shows t value (3.99) was statistically significant at 0.01 level of significance. It shows that there was significant difference found between male and female respondents. Male respondents mean score (Mean score $=3.62$ ) was higher as compare to female respondents score (Mean score $=3.39$ ). The effect size was found 0.35 that shows the large effect size between the two means.

Table 3

Dimensions of Reflective Practices (Comparison between Male and Female)

\begin{tabular}{|c|c|c|c|c|c|c|c|}
\hline $\begin{array}{c}\text { Dimensions of } \\
\text { Reflection }\end{array}$ & $\begin{array}{c}\text { Group } \\
\text { (Gender) }\end{array}$ & $\mathrm{N}$ & Mean & $t$ & $d f$ & $\begin{array}{l}\text { Sig (2- } \\
\text { tailed) }\end{array}$ & Cohen's d \\
\hline Reflection in & Male & 354 & 3.59 & 2.67 & 538 & .00 & 0.24 \\
\hline and on action & Female & 186 & 3.40 & & & & \\
\hline Tools for & Male & 354 & 3.49 & 4.67 & 538 & .00 & 0.41 \\
\hline reflection & Female & 186 & 3.18 & & & & \\
\hline Examining & Male & 354 & 3.72 & 3.39 & 538 & .00 & 0.29 \\
\hline perspectives & Female & 186 & 3.50 & & & & \\
\hline Questioning & Male & 354 & 3.69 & 2.94 & 538 & .00 & 0.26 \\
\hline assumptions & Female & 186 & 3.49 & & & & \\
\hline Ability to & Male & 354 & 3.63 & 3.33 & 538 & .00 & 0.29 \\
\hline reflect & Female & 186 & 3.41 & & & & \\
\hline
\end{tabular}

Table 3 shows that on first dimension of reflective practices $t$ value (2.67) was statistically significant at 0.01 level of significance. It shows that there was significant difference found between male and female respondents on 
'Reflection in and on action'. Male respondents (Mean score $=3.59$ ) were found better as compare to female respondents (Mean score $=3.40$ ). The effect size was found 0.24 that shows the medium effect size between the two means. On second dimension $t$ value (4.67) was statistically significant at 0.01 level of significance. It shows that there was significant difference found between male and female respondents on 'Tools of reflection'. Male respondents (Mean score $=3.49$ ) were found better as compare to female respondents (Mean score $=3.18$ ). The effect size was found 0.41 that shows the large effect size between the two means.

At third dimension t value (3.39) was statistically significant at 0.01 level of significance. It shows that there was significant difference found between male and female respondents on 'Examining perspectives'. Male respondents (Mean score $=3.72$ ) were found better as compare to female respondents (Mean score $=3.50$ ). The effect size was found 0.29 that shows the medium effect size between the two means. $t$ value (2.94) was statistically significant at 0.01 level of significance on fourth dimension of reflective practices. It shows that there was significant difference found between male and female respondents on 'Questioning assumptions'. Male respondents (Mean score $=3.69$ ) were found better as compare to female respondents (Mean score $=3.49$ ). The effect size was found 0.26 that shows the medium effect size between the two means. On last dimension $t$ value (3.33) was statistically significant at 0.01 level of significance. It shows that there was significant difference found between male and female respondents on 'Ability to reflect'. Male respondents (Mean score $=3.63$ ) were found better as compare to female respondents (Mean score $=3.41$ ). The effect size was found 0.29 that shows the medium effect size between the two means.

\section{Discussion}

Results revealed that majority of teachers believe they are practicing reflection on five dimensions including reflection in and on action, tools of reflection, examining perspectives, questioning assumptions and ability to reflect. These findings are aligned with the study conducted by Bibi and Aziz (2012) on 42 teachers from the universities of Islamabad and Rawalpindi, Pakistan to check the current situation of reflective practices 
of teachers, findings of the study revealed that teachers usually write diaries, encourage teaching management, follow the practice of student record keeping and management, get feedback from other colleagues, evaluate themselves, and coordinate well with colleagues and students. A study conducted by Ray and Coulter (2008) determine the depth of reflective practices among teachers and found similar results. Results are in line with the study conducted by Minott (2008) which shows that teachers mainly use both reflections in-action and on action. Bell and Mladenovic (2013) interviewed six tutors, revealing the way they think about reflection and reflecting practice as part of their teaching. Tutors have seen various benefits of reflection, including improving their teaching. Reflection before and after teaching is focus of tutors, but less during teaching. Reflection is triggered by negative events and positive feedback; some tutors participate in informal discussions about their teaching with their colleagues, seniors and friends. Sharar (2012) found that reflective practice is a big challenge for school teachers of Chitral to practice because of lack of knowledge about reflective practices, lack of time, professional development and pedagogical issues.

Significant difference was found regarding the self-reported reflective practices of male and female teachers at tertiary level. This finding is in consistent with the survey conducted by Rashidi and Javidanmehr (2012) on 190 school teachers in which significant difference was found between male and female teachers regarding their reflective practices. Poyraz and Usta (2013) also found that there is a significant difference among gender regarding their reflective practices. The results of the study are contradictory with the study of Odeh, Kurt and Atamtürk (2010) in which university teachers were examined by using self-report questionnaire to know that whether gender make a significant difference in the level of teacher reflection. Results revealed that gender does not play any role in teacher's reflection.

In present study with the help of self-reported views further it was found that male teachers are practicing reflection more as compared to female teachers in their reflective practices. These findings are contradict with the findings of some researches in which female reflective teachers outperformed men in reflective practices (Rashidi, Javidanmehr, 2012; 
Poyraz, Usta, 2013). The results of present study are in line with the study of Afshar and Farahani (2015) which found a significant difference between male and female teachers regarding reflective thinking and reflective practices in teaching. In present study as reported by results male respondents were found practicing more reflection as compare to female, it may be because male are more involved in their professional development and have more time to improve themselves in professional field, in our culture working female have more responsibilities they have to complete their home responsibilities and professional responsibilities both so maybe that's why they found less time for reflective practices.

\section{Conclusion}

The majority of respondents indicate that they practice reflection in action and on action, majority of respondents indicate that they use different tools for reflection, majority responded that they practice reflection by examining others and own perspective regarding their teaching, the majority of respondents claim that they practice reflective practice of questioning assumption, majority agrees that they have freedom to reflect. Overall results indicate that teachers believe that they are practicing reflection in their teaching at tertiary level. A significant difference was found among teachers by gender regarding their own assessments of their reflective practices in teaching. Male teachers were found to assess their reflective practices at a higher level than female teachers assessed their reflective practices. A significant difference was found among teachers by gender on the dimension reflection in and on action, tools of reflection, examining perspectives, questioning assumptions and ability to reflect.

\section{Recommendations}

It is recommended that universities may allocate special time for conducting reflective trainings and awareness seminars for teachers with special focus on female teachers. Reflective practitioners are recommended to discuss various situations and events so as to naturally cultivate reflections and follow teachers' values and exploration spirit. The opportunities for discussion also allow teachers to question and are 
questioned. It is recommended to incorporate practical approaches to reflection into practice in teacher in-service training programs by introducing models and techniques of reflection. In future researchers may deal with other demographic differences like socio-economic background, level of teaching, pre-service and in-service teachers and other with a larger sample size. 


\section{References}

Afshar, H. S. \& Farahani, M. (2015). Reflective Thinking and Reflective Teaching Among Iranian EFL Teachers: Do Gender and Teaching Experience Make a Difference? ELSEVIER Social and Behavioral Science, 192, 615-620.

Belenky, M. F., Clinchy, B. M., Goldberger, N. R., \& Tarule, J. M. (1986). Women's ways of knowing: The development of self, voice and mind. New York: Basic Books.

Bell, A. \& Mladenovic, R. (2013). How tutors understand and engage with reflective practices. Reflective Practice International and Multidisciplinary Perspectives, 14(1), 1-11.

Beveridge, I. (1997). Teaching your students to think reflectively: The case for reflective journals. Teaching in Higher Education. Queeb's University of Belfast, Northern Ireland.

Bolton, G. (2010). Reflective Practice. $3^{\text {rd }}$ ed. London: Sage.

Bound, D., Keogh, R., Walker, D. (1985). Reflection: turning experience into learning. London: Kogan Page.

Brookfield, S. (1995). Becoming a Critically Reflective Teacher. San Francisco: Jossey Bass.

Bibi, H. \& Aziz, S. (2012). Reflective Practices and Teacher Educators: An Exploratory Study. International Journal of Social Sciences and Education, 3(1), 08-15.

Csank, A. R. \& Conway, M. (2004). Engaging in Self-Reflection Changes Self-Concept Clarity: On Differences Between Women and Men, and Low-and High-Clarity Individuals. Sex Roles, 50(7/8), 469-480.

Finlay, L. (2008). Reflecting on Reflective practice. Practice-based Professional Learning Journal, 52, 1-27.

Gay, L.R., (1987). Educational research: Competencies for analysis and application, Merrill Publishing Company Chio, 101-102.

Ghaye, T., \& Lillyman, S. (2000). Reflection: Principles and practice for healthcare professionals. Wiltshire, UK: Quay Books.

Johns, C (1995). Framing learning through reflection within Carper's fundamental ways of knowing in nursing'. Journal of advanced nursing, 22 (2), 226-34. 
Korthagen, F.A. (1993). Two modes of reflection. Teaching and Teacher Education, 9(3), 317-326.

Krejcie, R. V., \& Morgan, D. W. (1970). Determining sample size for research activities. Educational and Psychological Measurement, 30, 607-610.

Loughran, J. J. (2006). A response to Reflecting on the self. Reflective Practice, 7, 43-53.

Minott, M. A. (2008). Valli's typology of reflection and the analysis of pre-service teachers' reflective journals. Australian Journal of Teacher Education, 33(5), 55-65.

Moon, J. (2005). Guide for Busy Academics No.4: Learning Through Reflection. Higher Education Academy.

Narelle, L. (2007). Take a photograph: teacher reflection through narrative. Reflective Practice International and Multidisciplinary Perspectives. 8(2), 177-191.

Odeh, Z., Kurt, M., \& Atamtürk, N. (2010). Reflective practice and its role in stimulating personal and professional growth. Available at http://www.qou.edu/english/conferences/firstNationalConferenc/ pdfFiles/zaidOdeh.df, Retrieved on 16-11-2017.

Poyraz, C., \& Usta, S. (2013). Investigation of preservice teachers' reflective thinking tendencies in terms of various variances. International Journal on New Trends in Education \& Their Implications, 14(12), 126-136.

Raelin, J. (2002). I don't have time to think! Versus the art of reflective practice. Reflections. Northeastern University.

Rashidi, N., \& Javidanmehr, Z. (2012). The status of reflective teaching among Iranian EFL teachers: Gender, academic degree and educational background scrutinized. Language and Literature: European Landmarks of Identity, 1(10), 493-502.

Ray, B. B., \& Coulter, G. A. (2008). Reflective Practices among Language Arts Teachers: The use of weblogs. Contemporary Issues in Technology and Teacher Education, 8(1), 6-26.

Rushton, I. \& Suter, M. (2012). Reflective Practice for Teaching in Lifelong Learning. McGraw-Hill Education: Open University press. 
Sammaknejad, A. \& Marzban, A. (2016). An Analysis of Teachers' Selfreflection on Classroom Management. Theory and Practice in Language Studies, 6(1), 84-89.

Schön, D. A. (1983). The reflective practitioner: How professionals think in action. New York, NY: Basic Books, Inc.

Schön, D. A. (1991). Concluding comments, in D.A. Schön (Ed.) The Reflective Turn: case studies in and on educational practice. New York: Teachers College Press.

Sellars, M. (2014). Reflective Practice for Teachers. London: Sage Publications.

Sharar, T. (2012). Introducing reflective practice to teachers in an English medium lower secondary private school in Chitral. Academic Research International, 2(3), 277-284.

Wilkes, L. L. \& Chapman, A. (2015). Reflective Practice Self-Assessment Instrument. Available at https://www.businessballs.com/free pdfmaterials/reflective-practiceself assessment.pdf . Retrieved on 12-07-2016.

Xavier, F. (2009). Teacher development using group discussion and reflection. Reflective Practice International and Multidisciplinary Perspectives, 10(4):529-541.

Zeichner, K., \& Liston, D. (1996). Reflective teaching: An Introduction. Mahwah, New Jersey: Lawrence Erlbaum Associates.

Zeichner, K. M \&, Liston, D. P. (2014). Reflective Teaching: An Introduction. New York: Routledge.

Citation of this Article:

Arshad, M., \& Malik, A.B. (2018). Reflective practices at tertiary level: A gender wise comparison. Pakistan Journal of Education, 35 (3), 187-202. 